\title{
COMPARATIVE STUDY OF TECHNOLOGIES FOR EXTRACTION OF BIOLOGICALLY ACTIVE SUBSTANCES FROM THE RAW MATERIAL OF ANIMAL ORIGIN
}

\author{
Ekaterina R. Vasilevskaya, Marina A. Aryuzina, Evgeniya S. Vetrova \\ V. M. Gorbatov Federal Research Center for Food Systems of Russian Academy of Sciences, Moscow, Russia
}

\begin{abstract}
Keywords: extraction, $p H$, pancreas, low molecular weight proteins, porcine
\section{Abstract}

Technologies of isolation and concentration of biologically active substances, developed in the middle of the $20^{\text {th }}$ century, need adjustment and adaptation to modern conditions both to increase the activity of substances and for greater economic efficiency. The aim of the research is the comparison of dynamics of biologically active compounds extraction from porcines pancreas in two methods: the saline method based on $0.9 \%$ sodium chloride solution, and the acidic method based on $2.4 \%$ trichloroacetic acid solution. Also the purpose of research is to assess the possibilities for further optimization of technologies. The total protein concentration based on the biuret reaction in the samples taken during the extraction, as well as the calculation and analysis of the point degrees and rates of extraction are chosen as the controlled parameters. Local maxima of the protein yields into the extractant media at the $60^{\text {th }}, 135^{\text {th }}$ and $255^{\text {th }}$ minute were recorded during saline extraction; and at the $75^{\text {th }}$ and $135^{\text {th }}$ minute during acid extraction. Also the proteomic profile of the extracts was studied. Wide range of compounds with molecular weight of less than $52 \mathrm{kDa}$ was found in extracts based on physiological saline solution, and protein substances of whole presented range of molecular weights in trichloroacetic acid based extracts were considered. The predominance of low molecular weight protein fraction of interest was noted also in this method of extraction in comparison with the other methods of extraction. According to the UniProt database, we assume availability of probable compounds with a molecular weight of less than $30 \mathrm{kDa}$ in the purified acidic extract. The presence of some proteins absent in the final saline extract was noted. The acidic erythrograms showed a weak degrading effect of both types of extracts on the membranes of rat erythrocytes, as well as the cytoprotective effect of acidic ultrafiltrates (less than $3 \mathrm{kDa}$ ). The obtained results prove a better efficiency of trichloroacetic acid extraction method used for obtaining a mixture of a wide range of compounds, including biologically active substances of low molecular weight.
\end{abstract}

\section{Funding:}

The research was supported by state assignment of V. M. Gorbatov Federal Research Centre for Food Systems of RAS, scientific research No. FNEN-2019-0008.

\section{Introduction}

The study and optimization of technologies for isolation of biologically active compounds from animal raw materials are today one of the most important aspects of modern biotechnology. Along with the fast development of the analytical chemistry and biochemistry spheres, the technological execution of methods, aimed to supervision and control of the observed processes, requires timely improvement to match the progress. In this regard, the permissible limits of sensitivity of the detection devices are improved, devices are designed with functional possibility to run combined experiments (for example, HPLC with a diode-matrix UV-visible spectrophotometric detector (DMD), fluorimetric MS-detector, capillary electrophoresis with DMD [1], low molecular weight electrophoresis combined with mass spectrometry of inductively coupled plasma [2]). The databases of discovered compounds are being replenished more and more (for example, refer to the UniProt protein database) [3]. The early studies, replicated on the currently obsolete equipment, were as accurate as it was possible for that time. Technologies based on such researches are still used today. By the way, these technologies often feature high cost, low efficiency and high labor intensity. In order to potentially reduce the economic costs of production, as well as to reduce the volume of waste, the dynamics of the process flow shall be studied in order to identify possible ways to optimize the methods.

In the $1920^{\mathrm{s}}$ insulin, pancreatin, glucagon, obtained from animal pancreas extracts, were patented. Later, the development of technologies for production of certain medical preparations of enzymes and hormones, extracted from porcine pancreas, went on. Pigs were used as a source of a whole range of important biologically active substances, and in the 30s of the last century, traditional approaches to the extraction of some specific compounds or their mixtures from the pancreas were developed. Those achievements serve as the basis of modern technologies [4,5]. Due to the rapid development of the technological execution of necessary compounds isolation, it can be assumed that the potential of this raw material is not fully achieved. 
Among the variety of extraction methods used to obtain biologically active substances from porcine pancreas, one can distinguish method of saline solutions (sodium and calcium salts), method of acidic solutions based on weak and strong acids, method of alcoholic solution based on ethyl alcohol, incl. the method of bismaceration [6]. Each of the method presented above has its specific advantages. The main advantage of physiological saline extraction is the absence of aggressive agents and the proximity of the conditions to natural, which matters for the recipient organism. Acid extraction by trichloroacetic acid (TCA) provides an acidic reaction medium, which contributes to inactivation of the main proteolytic enzymes of the pancreas and inhibits autolysis. Alcohol extraction allows achieving a better degree of the active substance extraction due to the partial disintegration of tissues exposed to organic solvent (ethanol). The disadvantage of technologies that include the use of acids or organic solvents is the necessity to remove them from the obtained ready extract. Despite the obvious difficulties related to this task, those technologies are still often used in production of medical preparations based on an extract of the pancreas, since they allow obtaining a higher yield of specific compounds. Alcohol extraction technology, which is often used to obtain insulin, can be considered as potential for further study in the prospect of comparing it with the methods discussed in this article.

At this stage it is of scientific interest to compare the methods of saline extraction and acid extraction. First of all, this is reasoned by very different conditions of the process described above, namely - the acidity of the medium, duration of the extraction, nature of the extractants, and the purification stage. The technologies under consideration also allow running the process at low temperatures for a long time, which has a positive effect on the results of the analysis of the protein composition and provides a better yield of native low molecular weight compounds.

The aim of the article is to study and compare the saline and acidic method of extraction of biologically active compounds of protein range from porcine pancreas, as well as to determine the efficiency of the considered technologies for obtaining a highly active complex of substances rich in low molecular weight components.

The absence of aggressive conditions during extraction process in physiological saline medium implies a higher content of protein substances in the extracts, which are also rich in the low-molecular fraction, which was partially replenished during the extraction as a result of the action of proteases. A high activity of low molecular weight fraction in the acid ultrafiltrate is expected. This is primarily caused by decrease in proteolytic enzymes activity in an acidic medium, as well as by the additional stage of purification from ballast inactive proteins.

\section{Objects and methods}

The object of the study was porcine pancreas Sus scrofa, sampled at Limited Liability Company "Pushkinskiy Dvor" (Russia, Pushkino). The raw materials were subjected to extraction by two methods: aqueous saline (physiological saline) and acidic (trichloroacetic acid), followed by study of obtained extracts and their ultrafiltrates.

The raw materials were frozen and stored at a temperature of minus $(40 \pm 2)^{\circ} \mathrm{C}$ with further thawing immediately before the study at a temperature of $(22 \pm 2)^{\circ} \mathrm{C}$. Before extraction, the pancreas was also subjected to fine grinding with the help of a meat grinder (Kenwood, England): mesh of 100 holes with a diameter of $3 \mathrm{~mm}$. The extraction scheme is shown below in Figure 1.

Saline extraction [7] was conducted in $0.9 \%$ sodium chloride solution by way of mixing of the finely chopped raw materials and an extractant in hydromodule in ratio of 1:5. The process lasted for 330 minutes. After completion of the extraction, the obtained solution was centrifuged in a Centrifuge CM-6M (ELMI, Latvia) at $3500 \mathrm{rpm}$ for $8 \mathrm{~min}$. at a temperature of $(22 \pm 2)^{\circ} \mathrm{C}$. Then, the supernatant liquid, separated from the sediment, was saved for further analyses. To study the extraction process, samples were taken throughout the entire process: at 0, 5, 10, 15 minutes; and further every 15 minutes till to $330^{\text {th }} \mathrm{min}$. Each sample was centrifuged for 5 minutes immediately after its sampling at a temperature of $4{ }^{\circ} \mathrm{C}$ on a Centrifuge 5427R (Eppendorf AG, Germany) at a speed of $3500 \mathrm{rpm}$; the supernatant liquid was frozen.

In case of acid extraction [8,9], the finely chopped raw material was loaded into the processor bowl together with an extractant $-2.4 \%$ trichloroacetic acid solution with a hydromodule of 1:3.15. The acid extraction technology also included the stage of the final extract purification from ballast proteins: primary centrifugation was run in a Centrifuge 5427R (Eppendorf AG, Germany) at 6,861 rpm for 10 minutes with cooling the extract to $4{ }^{\circ} \mathrm{C}$; the process also included the precipitation with sodium hydroxide solution at $\mathrm{pH}$ 6.2-7.2. The final centrifugation was run at 3,500 rpm for 10 minutes on a Centrifuge CM-6M (ELMI, Latvia) at a temperature of $(22 \pm 2)^{\circ} \mathrm{C}$. Extraction was conducted in the same laboratory installation, that was used for saline extraction, for 2 hours 15 minutes with sampling at $0,5,15$ minute and then every 15 minutes till to $135 \mathrm{~min}$. Each sample was centrifuged at $6,861 \mathrm{rpm}$ for 10 minutes. when cooled to $4^{\circ} \mathrm{C}$. The supernatant liquid was frozen at a temperature of minus $(40 \pm 2)^{\circ} \mathrm{C}$.

In both cases, the extraction process was conducted by the laboratory unit in LDU (Labotex, Russia) along with cooling down to $(4 \pm 2)^{\circ} \mathrm{C}$ in order to avoid autolysis, at a stirring speed of $400 \mathrm{rpm}$. The supernatant liquids of the purified extracts obtained after centrifugation were frozen at a temperature of minus $(40 \pm 2)^{\circ} \mathrm{C}$ and stored for no more than a month.

To obtain a highly active low molecular weight fraction of the extracts, the extracts underwent ultrafiltration on filters with a permeability limit of $3 \mathrm{kDa}$ (Amicon, Ireland) as the final stage of the technology process. The process was carried out on a Centrifuge 5427R (Eppendorf AG, Germany) at a speed of $11,481 \mathrm{rpm}$ for 20 minutes at a temperature of $4^{\circ} \mathrm{C}$. 


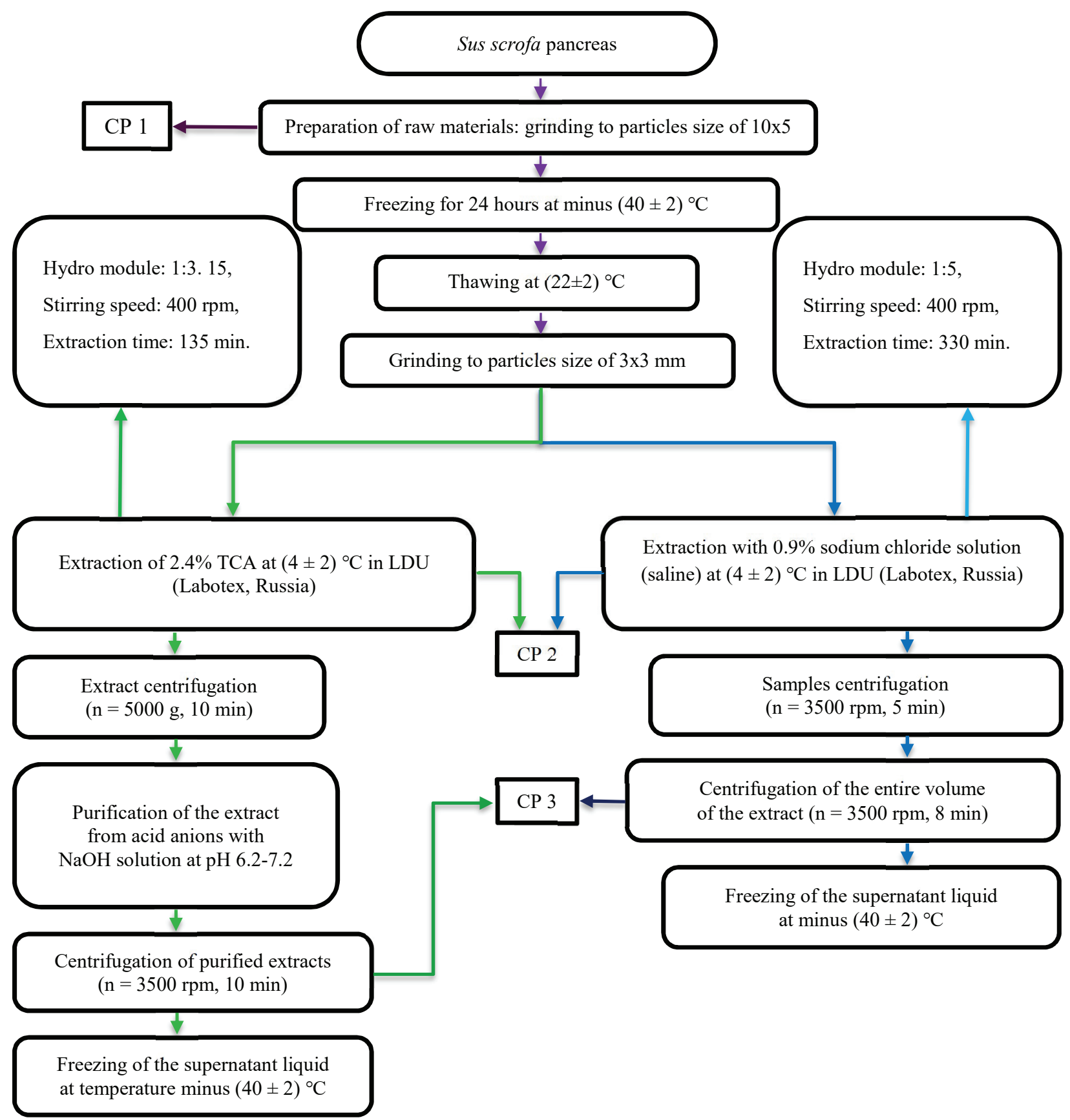

Figure 1. Scheme of extractions based on saline and trichloroacetic acid

Legend: CP1 - control point for native pancreas sampling to obtain a comparative sample (CS); CP2 is the control point for sampling of extracts to study the dynamics of both extraction methods; CP3 - control point of the final extract sampling: after centrifugation of the total volume of the extract - for saline extraction; after purification and secondary centrifugation — for acid extraction

In the samples taken during the extraction, the total protein concentration, the total proteolytic activity of enzymes, and the dynamics of the yield of protein compounds were analyzed by the proteomic profile. The membranotropic effect of biologically active compounds in primary purified extracts, as well as in their ultrafiltrates were studied.

Sample of the raw material (pancreas native - further $\mathrm{PN}$ ) were prepared in a known way [7].

The total protein concentration and ultrafiltrates in the extracts were measured on the basis of the biuret reaction according to the Kingsley-Weixelbaum method [10]: $600 \mu \mathrm{l}$ of the biuret reagent was incubated with the test sample, and after 10 minutes the optical density of the solution was measured at $540 \mathrm{~nm}$ by a photometer BioChem SA (HTI, USA).

On the basis of parameters of protein yield to the extractant the basic characteristics of the process like degree and rate of extraction were determined.

The degree of extraction was determined as the ratio of the extracted substance (protein) mass to the total mass of raw material and was calculated by the following formula:

$$
D=\frac{M}{m} \times 100 \%
$$

where

$M$ - is the mass of the extracted substance, g;

$m-$ is the total mass of the initial raw material in the mixture, $\mathrm{g}$. 
The point rate of extraction was determined by change in protein concentration (extracted substance) along the vector of time. It was calculated at each moment of the extraction process. Calculations were conducted by the formula:

$$
v=\frac{\Delta c}{\Delta t}=\frac{\mathrm{d} c}{\mathrm{~d} t}
$$

where

$c-$ is concentration of protein in extract, $\mathrm{g} / \mathrm{l}$;

$t-$ is corresponding time of the extraction, min.

The total proteolytic activity of the final extracts was determined by Leilian-Folgard method, which included heating in a test flask up to $37^{\circ} \mathrm{C}$ in a water bath of $20 \mathrm{ml}$ of $5 \%$ alkaline casein solution with $10 \mathrm{ml}$ of the test sample for 60 minutes. In a control flask, a solution of the same composition, immediately after mixing was precipitated first with a $0.2 \mathrm{~N}$ hydrochloric acid solution, and then with a $15 \%$ sodium sulfate solution. The precipitated fallout was filtered off. After one hour of sample exposure in a test flask, the same operations were carried out. Then $10 \mathrm{ml}$ of the obtained filtrate was transferred into clean flasks and titrated with 0.1 $\mathrm{N}$ sodium hydroxide solution in presence of $1 \%$ cresol red solution till obtaining the saturated bright crimson color. The proteolytic capacity was calculated from the difference in the volumes of sodium hydroxide required for titration of the experimental sample and control sample.

Membranotropic activity of biologically active compounds in extracts and ultrafiltrates was determined by constructing acidic erythrograms of erythrocyte membrane degradation $[11,12] .10 \mathrm{ml}$ of the test sample with a protein concentration of $1000 \mathrm{ng} / \mathrm{ml}$ on the basis of $0.9 \%$ sodium chloride solution that was introduced into a test flask. The control flask contained pure physiological saline. In both cases, $20 \mu \mathrm{L}$ of blood from rats' tails vein was added to the flasks, the contents were mixed for uniform contact of active compounds with erythrocytes and left to incubate at room temperature for 1 hour. After expiration of this time, $2 \mathrm{ml}$ of both samples were transferred into clean flasks and mixed with $2 \mathrm{ml}$ of $0.004 \mathrm{~N}$ sodium chloride-based hydrochloric acid solution. The dynamics of changes in optical density was recorded by SF-2000 spectrophotometer (Spektr, Russia) at $650 \mathrm{~nm}$ every 15 seconds from the moment of mixing until the end of hemolysis (when the optical density values reach a plateau), i. e. for at least 10 minutes.

The proteomic profile of the extracts was studied on the basis of electropherograms obtained by Laemmli method, i. e. by one-dimensional denaturing electrophoresis in $12.5 \%$ polyacrylamide gel in presence of SDS. The process was run in a VE-10 chamber (Helicon, USA) at a temperature of $(22 \pm 2)^{\circ} \mathrm{C}$ at $60 \mathrm{~V}$, until the samples reached the boundary of the separating gel, then at $130 \mathrm{~V}$ until the electrophoresis was completed. Standards (Fermentas, Lithuania) were used as comparison referential markers.

The analyzed samples were primary stained with $\mathrm{Coo}$ massie Brilliant Blue G-250 solution. Later the stain was removed by $10 \%$ acetic acid.
To increase the sensitivity level of this method, silver staining was performed according to Bloom's method by alternate incubation of the samples in solutions of sodium hyposulfite, of silver nitrate and sodium carbonate.

Density diagrams were obtained by the software ImageJ (National Institutes of Health, USA) [13] based on results of studying the proteomic profile of extracts selected during the extraction process at control points. The results were visually presented on the basis of automatic densitometric analysis of the scanned electropherograms. In order to avoid errors in study of various extractions electropherogram, the same parameters were set up. The image was converted to 8-bit type, then an area of 1280x1938 pixels was selected on the track. The molecular weight of the fractions was determined by correlating of the corresponding peaks on the density diagram of the test sample with the peaks of the standards $[14,15]$.

The software STATISTICA 10.0 was used for statistical processing of the total protein content. The final results were calculated and presented as "mean \pm standard error" $(\mathrm{M} \pm \mathrm{SE})$. Significant differences were checked using oneway analysis of variance ANOVA followed by Tukey's test. The deviations, when $\mathrm{P}$ values didn't exceed 0.05 , were considered as statistically significant [16].

\section{Results and discussion}

When measuring the total protein concentration (Figure 2) in the samples taken during the saline extraction, a sharp increase in the values from 0 to 5 minutes was observed. And the further decrease in the protein content in the samples was observed at $90^{\text {th }} \mathrm{min} .(21.2 \pm 2.7 \mathrm{~g} / \mathrm{l})$, at $165^{\text {th }} \mathrm{min}$. $(19.6 \pm 0.4 \mathrm{~g} / \mathrm{l})$, at $240^{\text {th }} \mathrm{min} .(19.7 \pm 0.2 \mathrm{~g} / \mathrm{l})$, at $270^{\text {th }}$ min. $(19.5 \pm 0.3 \mathrm{~g} / \mathrm{l})$. The observed maximum concentration values are explained by release of a new fraction of compounds into the extractant, for example, at $60^{\text {th }} \mathrm{min}$. $(23.1 \pm 0.9 \mathrm{~g} / \mathrm{l})$, which together with the concentration value for $135^{\text {th }}$ min. $(23.3 \pm 0.6 \mathrm{~g} / \mathrm{l})$ was the highest throughout the entire process of extraction. Minor increases in concentration were also observed at $195^{\text {th }}$ and $255^{\text {th }}$ min. In general, it is necessary to note the smooth way of change in the samples protein content, starting from $5^{\text {th }}$ min. of the process.

TCA extraction featured a smooth increase in total protein content up to $75^{\text {th }}$ minute, where it reached a maximum and amounted to $15.6 \pm 0.4 \mathrm{~g} / \mathrm{l}$. A further slight decrease in concentration led to coming of protein amount, released to extractant, to a plateau. This plateau values were was observed until the very end of the extraction process.

According to the diagram of dependence of the total protein concentration on time of extraction, in case of saline extraction a higher yield of protein into the extractant is evident throughout the entire process. From the first moments of the process, a sharp increase in the amount of protein was observed in comparison with a smooth increase of protein concentration in case of acid extraction. Both methods of extractions feature an oscillatory process of the protein content changing in the extracts. 


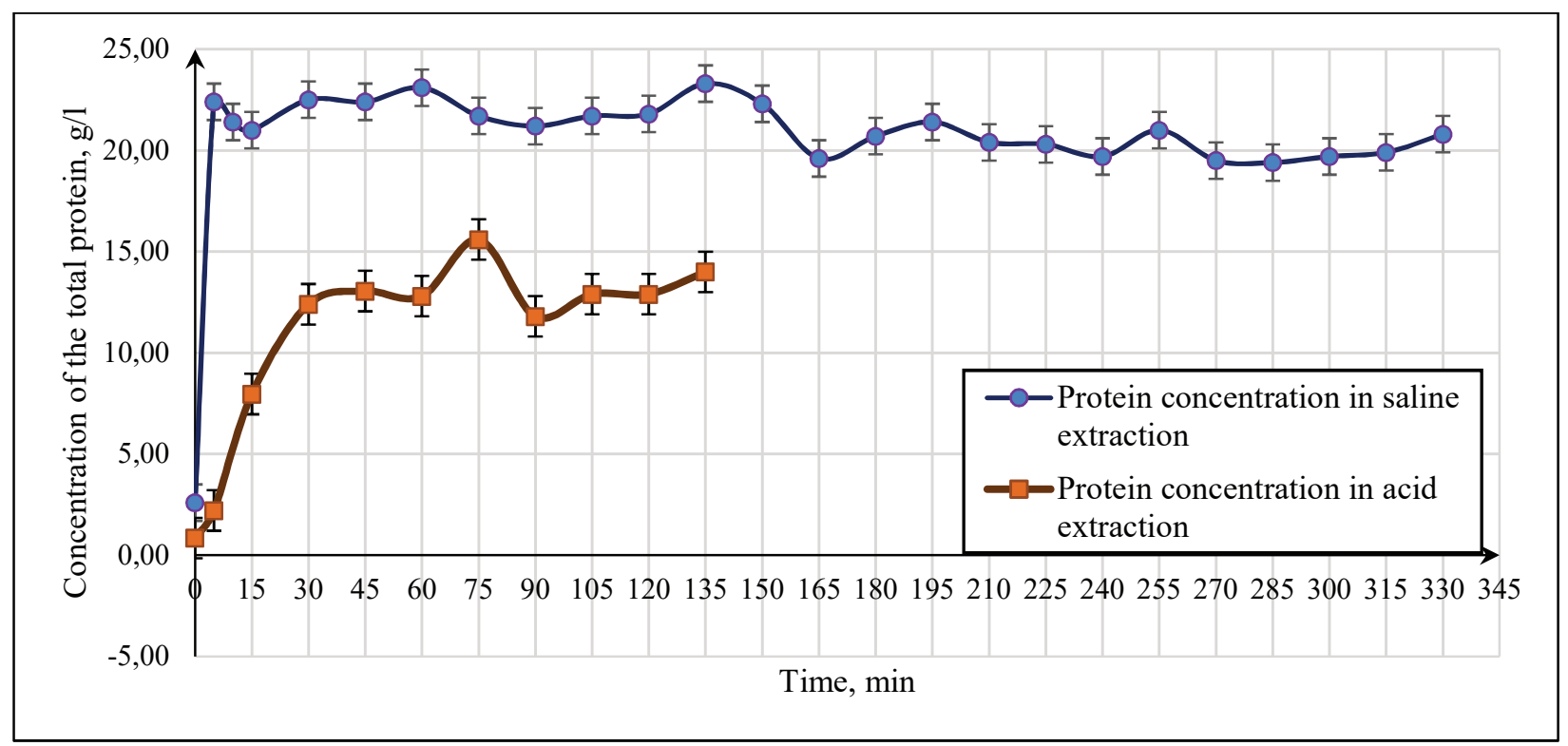

Figure 2. Diagram of the dependence of the total protein concentration in acid and saline extracts on the duration of the process

As result of processing the data on total protein concentration in the extracts, the degree (D) and point rate (v) of extraction were calculated for both methods. Diagram of the dependence of rate of proteins release into the extractant are shown below in Figure 3. It is necessary to note the high rate of saline extraction till the $5^{\text {th }}$ minute, in contrast to TCA extraction, in which the rate gradually increased up to the $15^{\text {th }}$ minute and then began to decrease uncritically. In both cases, the process showed an oscillatory change in the rate within the range of $0 \mathrm{~g} /\left(1^{*} \mathrm{~min}\right)$, i. e. in general the release of protein into the extractant took approximately constant values with minor deviations. Thus, there was a slight decrease in rate of extraction at the $165^{\text {th }}$ and $270^{\text {th }}$ minutes in saline extraction, and at the $90^{\text {th }}$ minute in case of TCA extraction.

The data on degree of extraction are shown above in the Table 1. It is necessary to note the correlation with the data on the total protein content in the extracts. The final degree of extraction of the protein component in the saline variant exceeded 2.25 times the value of $\mathrm{D}$ for acid extrac- tion. It proves that the saline solution is more efficient as an extractant in terms of this regard. The highest degree of extraction (Table 1, light green line) was observed from the $30^{\text {th }}$ till $150^{\text {th }}$ minute, and at the $75^{\text {th }}$ minute. (Table 1 , red line) for extracts based on $0.9 \%$ sodium chloride solution and TCA, respectively.

The study of proteolytic activity of enzymes in the final extracts showed a higher value in the case of saline solution extraction and amounted to $94,276 \mathrm{U} / \mathrm{ml}$ in comparison with $33,748 \mathrm{U} / \mathrm{ml}$ for the TCA-based sample. The data indicate the best enzymatic activity in the saline extract, which is primarily associated with mild environmental conditions (neutral $\mathrm{pH}$, the absence of denaturing agents that can negatively affect the active centers of enzymes, etc.). The low proteolytic capacity of the acid extract indicates an insufficient degree of purification of active enzymes from the inhibitory action of TCA, even after the completion of additional stages of purification. The reason may also be the removal of enzymes fraction together with the ballast proteins

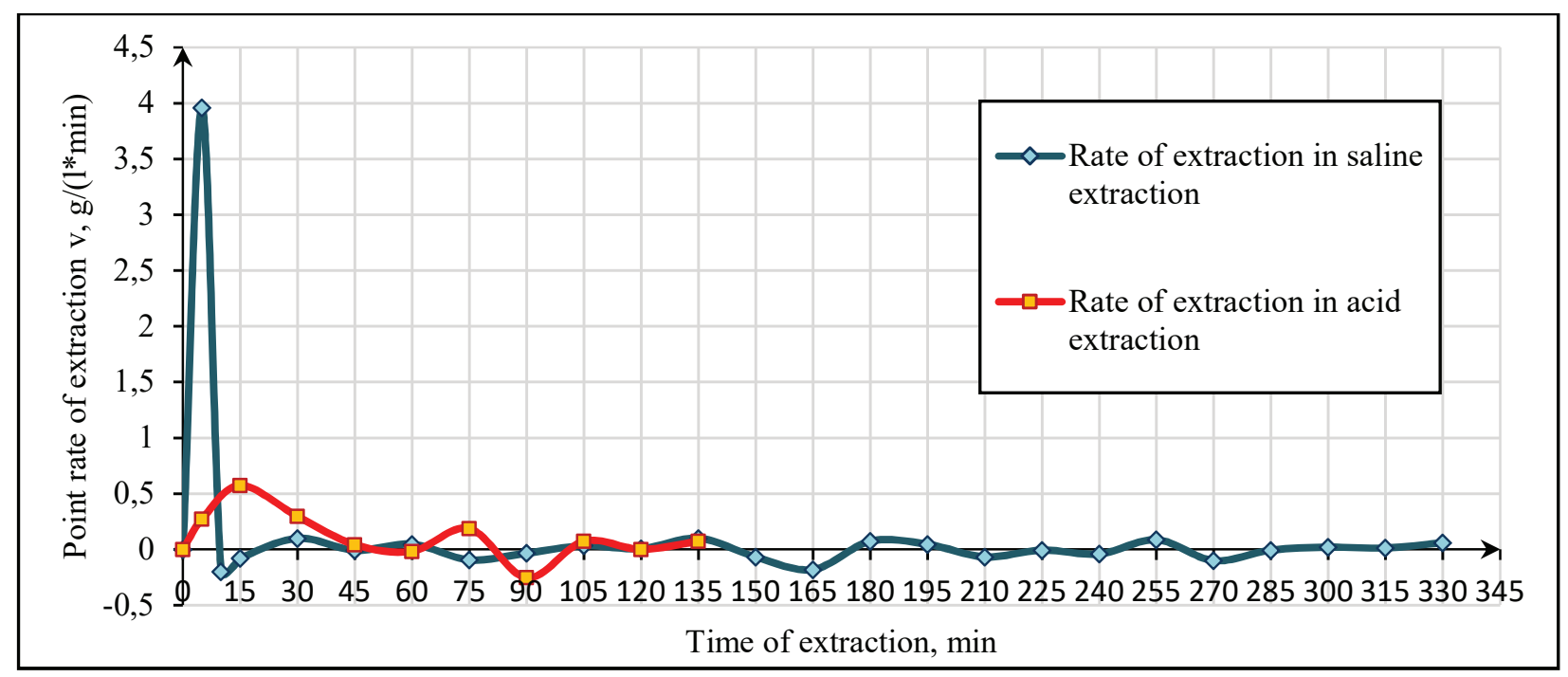

Figure 3. Diagram of the change in the point rate of extraction for saline extraction and for acid extraction 
Table 1. Extraction rate of protein-peptide fraction in the process of saline and acid extraction

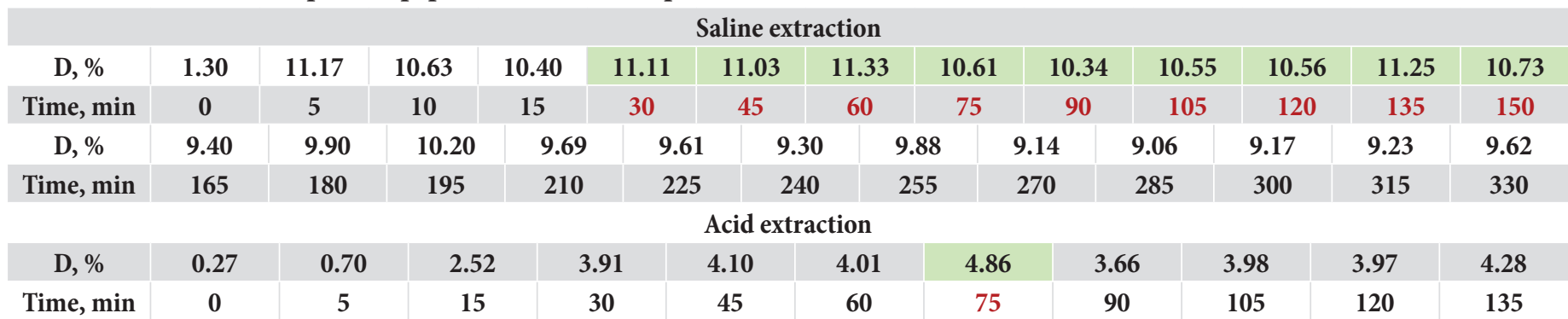

precipitated at the stage of neutralization and centrifugation. It is necessary to keep in mind that a decrease in proteolytic activity may be a positive factor, indicating that many large and medium-sized proteins, that avoided the undesirable process of autolysis, are preserved in their native form.

To obtain information on the biological activity of the low molecular weight fraction, ultrafiltration was conducted. The data on the total protein concentration in the final investigated extracts and their ultrafiltrates are presented below in the Table 2 .
Table 2. Total protein concentration in extracts before and after ultrafiltration

\begin{tabular}{|c|c|c|}
\hline \multirow{2}{*}{ Extraction variation } & \multicolumn{2}{|c|}{ Total protein concentration, $\mathrm{g} / \mathbf{1}$} \\
\cline { 2 - 3 } & Final extract & Ultrafiltrate \\
\hline Saline & $23.3 \pm \mathbf{0 . 6}$ & $\mathbf{6 . 0 3} \pm \mathbf{0 . 1}$ \\
\hline Acidic & $10.8 \pm 0.1$ & $\mathbf{8 . 0 4} \pm 0.2$ \\
\hline
\end{tabular}

The results of the analysis of erythrograms obtained with acid inhibition of rat blood erythrocytes after its incubation with extracts (Figure 4) and their low-molecularweight fractions (Figure 5) proved a short-term hemolysis and a tendency for a smooth decline in all samples.

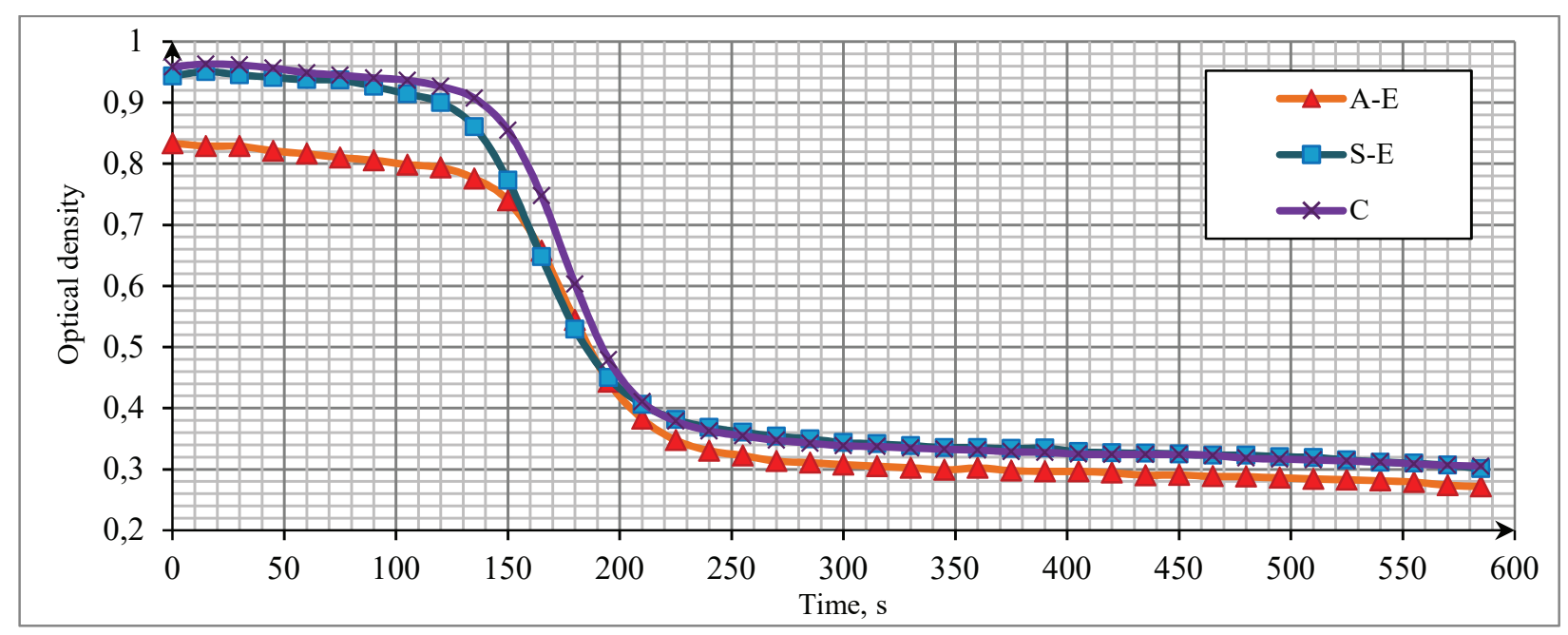

Figure 4. Acidic erythrograms of erythrocytes incubation with the original extracts.

Legend: A-E - curve of incubation of erythrocytes with TCA extract; S-E - curve of incubation of erythrocytes with saline extract; $\mathrm{C}$ - curve of incubation of erythrocytes with saline solution without the sample

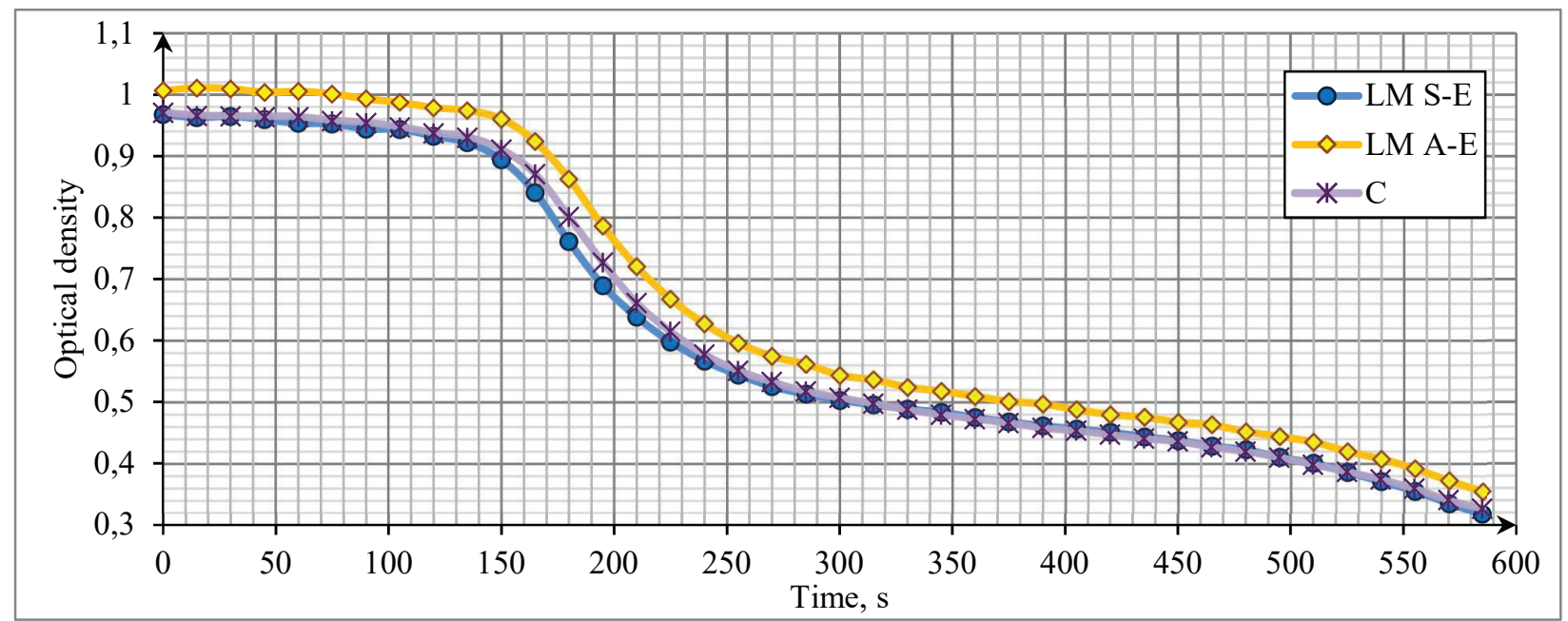

Figure 5. Acidic erythrograms of incubation of erythrocytes with ultrafiltrate extracts.

Legend: LM A-E - incubation curve of erythrocytes with low molecular weight fraction of TCA extract; LM S-E - incubation curve of erythrocytes with low molecular weight fraction of saline extract; $\mathrm{C}$ - curve of incubation of erythrocytes with saline without a sample 
Analysis of the diagram typical for incubation of erythrocytes with primary extracts (Figure 4) revealed particularly low optical densities for the TCA extract, which is explained by the presence in the sample of a large number of biologically active compounds that can penetrate through the membrane and accelerate the process of its degradation. In addition, this hemolysis curve is also spanned below the control sample curve, which confirms the overall negative effect of the extract on biological membranes. The results of determining the optical density of erythrocytes in the case of incubation with a saline extract were similar to the values in the control sample at the very beginning of the process and at the end of hemolysis. The decline in the diagram, that indicates the process of direct cells destruction, was found below the control curve and almost coincided with the values for the acid extract, which indicates a high degree of membrane degradation. Based on the results of the analysis, it can be concluded that the primary extracts are unable to provide cytoprotective effect on biological membranes, which is more profound in the TCA-based sample. In this regard, it is possible to assume the possible presence of highly active compounds in the samples, capable to transport substances through the membrane, which indirectly leads to its destruction.

A similar process was observed in the case of saline ultrafiltrate (Figure 5). The incubation diagram with erythrocytes also coincided with the control curve, which proves a weak membranotropic activity of the low molecular weight fraction in this sample. An obvious difference was observed when considering the acid ultrafiltrate curve. High values of the optical density of the sample based on TCA confirmed the cytoprotective effect of biologically active substances released into the extract, as well as an increase of erythrocyte membrane preservation level being exposed to degrading agent - hydrochloric acid.

Analysis of the proteomic profile of the final extracts (refer to Figure 6) showed the range of protein compounds on electropherogram at the final point of saline extraction (the $330^{\text {th }}$ min. - Figure 6, No. 1) and track of the raw material (Figure 6, No. 2) corresponding to the pancreas sample, which was not subjected to extraction. Compounds within the range of $52 \mathrm{kDa}$ and less were found in the extracts, which were discussed in detail in our previous research [7]. It should be noted that the fractional bands in this extract are more saturated than the primary electropherogram of acid extraction (Figure 6, No. 3, 4). In case of acid extraction only a few slightly expressed protein fractions were observed in the range of more than $250 \mathrm{kDa}, 69-70 \mathrm{kDa}$, $52 \mathrm{kDa}, 22-23 \mathrm{kDa}$ and $15 \mathrm{kDa}$. The visual analysis of the native track of purified acid extract found no difference from the track of extraction 135 minutes long. The staining with silver (Figure 6, No. 5) revealed a wide profile of protein compounds in whole presented range of molecular weights. In the track of the purified extract (refer to Figure 6, No. 6), some medium-molecular fractions were absent:
$70-95 \mathrm{kDa}, 32-48 \mathrm{kDa}$; the fraction $15-16 \mathrm{kDa}$ became less saturated, and the intensity of the low-molecular fraction of weight of less than $8 \mathrm{kDa}$ increased slightly.

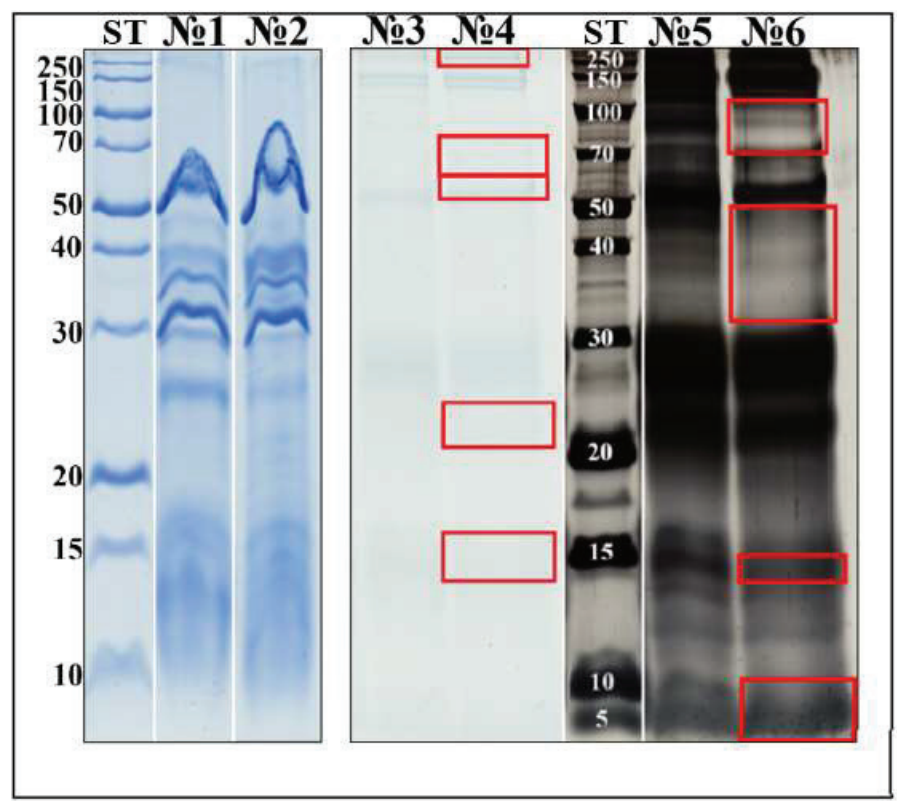

Figure 6. One-dimensional electropherogram of porcine pancreas extracts

Legend: ST - molecular weights standards: 250, 150, 100, 70 50, 40, 30, 2015,10 and $5 \mathrm{kDa}$; No. 1 - track of the endpoint of saline extraction; No. 2 - track of the sample not subjected to extraction (PN); No. 3 - track of the endpoint of acid extraction; No. 4 - track of purified acidic extract; No. 5 - silver-stained acid extraction endpoint track; No. 6 - silver stained track of a purified acid extract. Significant positions of fractional bands or changes in fractional composition are marked red

The densitometric study of native electropherograms of acid extracts in the ImageJ software brought little information, since only 5 weak peaks were identified at the endpoint of extraction and in the purified extract too (Figure 7, No. 3, 4). After silver staining, a greater number of fractions were found on the corresponding tracks diagram within entire presented range of molecular weights. This range featured prevalence of fractions over $100 \mathrm{kDa}$, 83-90 kDa, 70-75 kDa, 43-65 kDa, $18-32 \mathrm{kDa}, 14-16 \mathrm{kDa}$, less than $11 \mathrm{kDa}$. After purification of the extract some of the protein compounds were removed, and that provided better separation of the peaks in these specified ranges of masses. Thus, peaks at $137-140 \mathrm{kDa}, 110 \mathrm{kDa}, 100 \mathrm{kDa}$, $70 \mathrm{kDa}, 52 \mathrm{kDa}, 41-42 \mathrm{kDa}, 27-31 \mathrm{kDa}$, and $21 \mathrm{kDa}$ were clearly distinguishable. The absent peaks in the density diagram (49-50 kDa, 33-34 kDa, 16 and $11 \mathrm{kDa})$ most likely corresponded to the removed ballast proteins.

During saline extraction (Figure 7, No. 1) and analysis of the sample not subjected to extraction (Figure 7, No. 2), a large number of similar peaks were noted: a profound peak at $52 \mathrm{kDa}$, a row of clear minor peaks with varying degrees of manifestation within the range $32-47 \mathrm{kDa}$, at $30 \mathrm{kDa}$, the peaks at $24-25$ and $29 \mathrm{kDa}$ were expressed better in case of the saline extraction, as well as the low molecular weight fraction of $10-15 \mathrm{kDa}$ which was better visible too. 


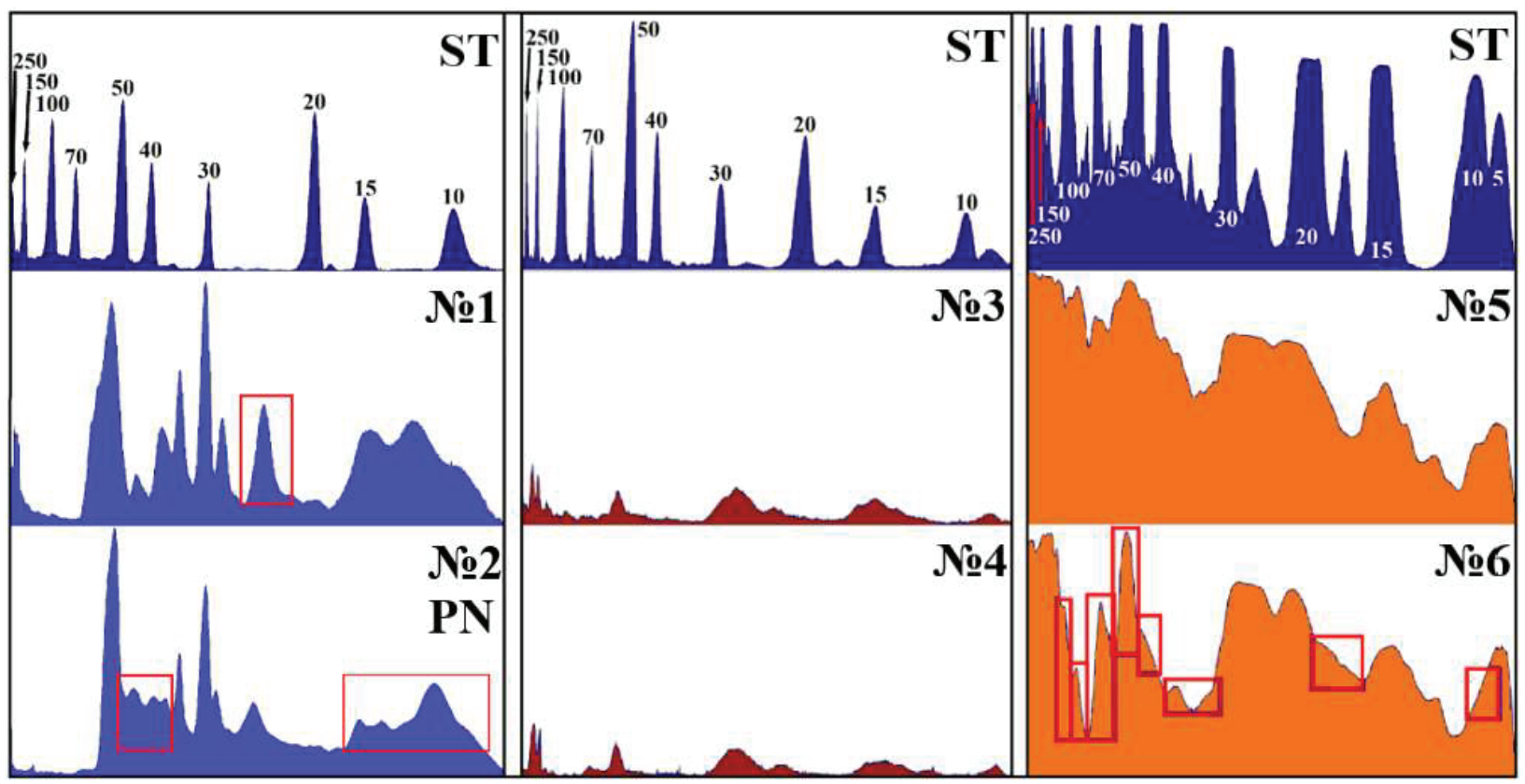

Figure 7. Histograms of the density of the protein fractions of the pancreas extraction.

Legend: ST - molecular weight standards: 250, 150, 100, 70 50, 40, 30, 2015,10 and $5 \mathrm{kDa}$; No. 1 - track of the endpoint of saline extraction (330 min); No. 2 - track of the sample not subjected to extraction (PN); No. 3 - track of the endpoint of acid extraction (135 min); No. 4 - track of purified acidic extract; No. 5 - silver stained acid extraction endpoint track;

No. 6 - silver stained track of a purified acid extract.

Significant changes in the fractional composition of the extracts are marked red

Analysis of electropherogram and corresponding density diagram by Image J software showed a wide range of compounds in all types of extracts. In case of acid extraction the high molecular weight proteins prevailed, which was detected by silver staining. The saturation of the protein bands prevailed in the saline extract and the track of the initial PN sample, which protein bands correlated with the previously presented data on the total protein content.

The analysis of dynamics of the biologically active protein substances extraction from porcine pancreas showed high values of the total protein concentration during saline extraction along with a wide range of compounds throughout the entire process. In case of acidic extracts the protein content values were lower; however, the proteomic profile of the samples taken during the process was characterized by a greater variety of fractions within the whole presented range of molecular weights. First of all, this may be explained by dependence of solubility $[17,18]$ and activity of many enzymes [19] secreted by the porcine pancreas on the acidity of the medium. Thus, as the $\mathrm{pH}$ approaches the isoelectric point of a protein, its solubility decreases when it reaches its minimum at $\mathrm{pI}$ value [20]. This indicator has long been established for many hydrolytic enzymes of the pancreas of cattle and pigs. It has been determined that most of the main enzymes are secreted by the organ under normal conditions in the form of pancreatic fluid. To the maximum extent, isoenzymes of $a$-amylase I and II, for example, precipitate at $\mathrm{pH} 6.5$ and 6.1, trypsin at $\mathrm{pH}$ 10.2-10.8, chymotrypsin at $\mathrm{pH} 8.1$, ribonuclease at $\mathrm{pH} 9.6$ [6,21-23]. In this regard the acidic environment created by TCA provides better solubility and, accordingly, a greater variety of compounds in extracts. In saline samples, due to physiological solution, a neutral reaction of the medium is established, which leads, to varying degrees, to a decrease in the yield of some compounds into the extractant. The lower concentration of total protein in acid extracts samples is also associated with inhibition of many digestive enzymes, since the maximum activity of pancreatic lipase is observed at $\mathrm{pH} 8-9$, trypsin 7-9, chymotrypsin 7.8-8.0, pancreatic elastase 8.5, carboxypeptidase A 8.0 [9,24-27]. Thus, a higher yield of pancreatic proteins, most of which are enzymes [28], is observed in case of neutral or slightly alkaline medium, since these $\mathrm{pH}$ values account for maximum activity of enzymes; this phenomena was also observed in case of saline extraction. On the other hand, high values of the protein concentration in these extracts can be caused by mild extraction conditions as those mild conditions provided extraction of active substances together with biologically active compounds of ballast proteins. The ballast proteins were removed from the extract in case of acid extraction by an additional purification stage.

Throughout the entire experiment, in both methods the oscillatory nature of the degree and rate of protein extraction from pancreas was observed. Decrease in these values at some moments of the process is explained by a decrease in amount of proteins released to the extractant or by their fermentative breakage as a result of autolysis caused by action of extracted proteolytic enzymes [29-32]. Decrease in proteases activity can be achieved by dropping down of the process temperature (which was done in this research), as well as by acidifying the extractants as indicated above. When using saline as an extractant, an instant increase in the extraction rate was observed due to absence of obvious inhibitory agents. For obvious reasons the extraction 
of TCA was accompanied by smooth increase in rate of protein release into the extractant. Based on the obtained results, it is possible to note the greater dependence of the extraction method efficiency on availability of inhibiting factors, as well as on the type of the extractant.

The fraction of interest with molecular weight of less than $30 \mathrm{kDa}$ in the final saline extract was researched in early works [7]. Using the UniProt database [3] the following low molecular weight compounds were presumably detected in the purified acid extract: chymotrypsin C $(28.9 \mathrm{kDa})$, a member of family of chymotrypsin-like elastases $1(28.8 \mathrm{kDa})$ and $2 \mathrm{~A}(28.7 \mathrm{kDa})$, glutathione S transferase omega-1 (27.4 kDa), kininogenase (27.2 kDa), proglucagon $(21 \mathrm{kDa})$, secretin $(14.6 \mathrm{kDa})$, trefoil factor 2 $(13.8 \mathrm{kDa})$, somatostatin $(12.7 \mathrm{kDa})$, colipase $(12.1 \mathrm{kDa})$, inhibitor of serine protease of Kazal-type $4(9.6 \mathrm{kDa})$ and $1(6 \mathrm{kDa})$, precursor of pancreatic hormone $(7.3 \mathrm{kDa})$ etc. Due to smaller amount of compounds in the saline extract, many of the above specified types of substances were not found there.

\section{Conclusion}

The study of dynamics of extraction based on $0.9 \%$ sodium chloride solution showed a higher concentration of total protein throughout the entire process with a wide range of compounds with molecular weight of less than 52 $\mathrm{kDa}$. In TCA extraction, the protein content in the analyzed samples was lower than in the first extraction method; however, analysis of the proteomic profile of the sam- ples showed a greater variety of compounds in the entire presented range of molecular weights. The low molecular weight fraction prevailed in acid extracts both before ultrafiltration (according to results of electropherograms study) and after ultrafiltration (based on analysis of protein content in the ultrafiltrates).

Using of the drawn acidic erythrograms enabled to detect the capability, peculiar for primary extracts, to destroy the biological membranes. The low molecular weight fraction of the acid extract possessed the highest cytoprotective effect, which proved the presence of highly active compounds in the extract.

When comparing the saline and acid extraction methods, the applicability of both modifications for obtaining a mixture of proteins with different molecular weights is noted. In this case, greater efficiency is observed in extraction with trichloroacetic acid. In result of this method it is possible to obtain a complex of low-molecular-weight highly active biological compounds.

It is necessary to note that the processes, considered in this work, require a comprehensive approach and are the subject of further extensive research. It is necessary not only to trace the dynamics of the process, but also to select target markers-compounds, which could be used to determine the efficiency of extraction, and also to study the potential for isolating of some specific compounds while maintaining of their high activity. The study of other extractants, for example, alcohol or sulfuric acid, is also considered a promising direction of researches.

\section{REFERENCES}

1. Eller, K.I., Perova, I.B. (2020). Trends in the development of analytical methods for determination of the quality and authenticity of foodstuffs. Problems of Nutrition, 89(4), 255-261. https://doi.org/10.24411/0042-8833-2020-10059 (In Russian) 2. Haider, S.R., Reid, H.J., Sharp, B.L. (2010). Modification of tricine-SDS-PAGE for online and offline analysis of phosphoproteins by ICP-MS. Analytical and bioanalytical chemistry, 397(2), 655-664. https://doi.org/10.1007/s00216-010-3588-9

3. Data base "UniProt". Retrieved from https://www.uniprot. org/ Accessed August 13, 2021

4. Karamanou, M., Protogerou, A., Tsoucalas, G., Androutsos, G., Poulakou-Rebelakou, E. (2016). Milestones in the history of diabetes mellitus: The main contributors. World Journal of Diabetes, 7(1), 1-7. https://doi.org/10.4239/wjd.v7.i1.1

5. Bobrovnichij, V.I., Vyazova, L.I. (2007). Enzymotherapy of digestive disorders in children. Medicinskij zhurnal, 2(20), 110111. (In Russian)

6. Ogasawara, M., Yoshii, K., Wada, J., Yamamoto, Y., Inouye, K. (2020). Identification of guanine, guanosine, and inosine for $\alpha$-amylase inhibitors in the extracts of the earthworm Eisenia fetida and characterization of their inhibitory activities against porcine pancreatic $\alpha$-amylase. Enzyme and Microbial Technology, 142, Article 109693. https://doi.org/10.1016/j.enzmictec.2020.109693 7. Vasilevskaya, E.R., Aryuzina, M.A., Vetrova, E.S. (2021). Saline extraction as a method of obtaining a mixture of biologically active compounds of protein nature from a porcine pancreas. Food Systems, 4(2), 97-105. https://doi.org/10.21323/26189771-2020-4-2-97-105 (In Russian)

8. Zabolockaya, E.R., Vinohodov, D.0. (2018). Modern methods of isolation and purification of enzymes. Separation of nucleases from proteolytic enzymes in extract of pancreas of cattle. Bulletin of the Saint Petersburg State Institute of Technology (Technical University), 47(73), 62-68. (In Russian)

9. Hart, P.A., Topazian, M., Raimondo, M., Cruz-Monserrate, Z., Fisher, W.E., Lesinski, G.B. et al. (2016). Endoscopic pancreas flu- id collection: methods and relevance for clinical care and translational science. The American Journal of Gastroenterology, 111(9), 1258-1266. https://doi.org/10.1038/ajg.2016.297

10. Vasilevskaya, E.R., Kotenkova, E.A., Lukinova, E.A., Kalinova, E.A. (2017). Research methodology of Sus scrofa tissue extracts protein-peptide components. Theory and Practice of Meat Processing, 2(3), 79-85. https://doi.org/10.21323/2414438X-2017-2-3-79-85 (In Russian)

11. Izmest'eva, O.S., Dzikovskaya, L.A., Zhavoronkov, L.P. (2020). Effect of rat exposure to moderate pressure oxygen atmosphere on resistance of erythrocytes against hemolysis. Bulletin of Experimental Biology and Medicine, 169(2), 201-204. https://doi. org/10.1007/s10517-020-04850-5

12. Vasilevskaya E. R. (2018). Complex assessment of biologically active substances of animal origin, possessing immunotropic activity. Vsyo o myase, 3, 32-35. https://doi.org/10.21323/20712499-2018-3-32-35

13. Ramió-Lluch, L., Prieto, O.B., Ramírez, A., Fernández-Novell, J.M., Peña, A., Rodríguez-Gil, J.E. (2019). "In vitro" capacitation and further progesterone-induced acrosome exocytosis are linked to specific changes in the expression and location of threonine phosphorylation of boar spermatozoa. Reproduction in Domestic Animals, 54(8), 1085-1094. https://doi.org/10.1111/rda.13478 14. Azeem, S.M.A., Madbouly, M.D., El-Shahat, M.F. (2019). Determination of nitrite in processed meat using digital image method and powdered reagent. Journal of Food Composition and Analysis, 81, 28-36. https://doi.org/10.1016/j.jfca.2019.05.003 15. Nogueira, M.H., Ben-Harb, S., Schmutz, M., Doumert, B., Nasser, S., Derensy, A. et al. (2020). Multiscale quantitative characterization of demineralized casein micelles: How the partial excision of nano-clusters leads to the aggregation during rehydration. Food Hydrocolloids, 105, Article 105778. https://doi. org/10.1016/J.foodhyd.2020.105778

16. Kupaeva, N.V., Kotenkova E. A. (2019). Search for alternative sources of natural plant antioxidants for food industry. Food 
Systems, 2(3), 17-19. https://doi.org/10.21323/2618-97712019-2-3-17-19

17. Panova, N.V. (2019). Features of the extraction of biologically active compounds of raw animal origin. Physico-chemical biology, 60-64. (In Russian)

18. Tan, Y., Chang, S.K. (2018). Isolation and characterization of collagen extracted from channel catfish (Ictalurus punctatus) skin. Food Chemistry, 242, 147-155. https://doi.org/10.1016/j. foodchem.2017.09.013

19. Jiang, S., Ding, J., Andrade, J., Rababah, T.M., Almajwal, A., Abulmeaty, M.M. et al. (2017). Modifying the physicochemical properties of pea protein by $\mathrm{pH}$-shifting and ultrasound combined treatments. Ultrasonics Sonochemistry, 38, 835-842. https://doi.org/10.1016/j.ultsonch.2017.03.046

20. Zhang, Y., Zhou, X., Zhong, J., Tan, L., Liu, C. (2019). Effect of $\mathrm{pH}$ on emulsification performance of a new functional protein from jackfruit seeds. Food Hydrocolloids, 93, 325-334. https://doi.org/10.1016/j.foodhyd.2019.02.032

21. Di Giosia, M., Valle, F., Cantelli, A., Bottoni, A., Zerbetto, F., Calvaresi, M. (2018). C60 bioconjugation with proteins: towards a palette of carriers for all pH ranges. Materials, 11(5), 691-101. https://doi.org/10.3390/ma11050691

22. Wei, X., Wang, Y., Chen, J., Xu, P. Zhou, Y. (2018). Preparation of ionic liquid modified magnetic metal-organic frameworks composites for the solid-phase extraction of $\alpha$-chymotrypsin. Talanta, 182, 484-491. https://doi.org/10.1016/j.talanta.2018.02.022 23. Barthold, S., Kletting, S., Taffner, J., de Souza CarvalhoWodarz, C., Lepeltier, E., Loretz, B. et al. (2016). Preparation of nanosized coacervates of positive and negative starch derivatives intended for pulmonary delivery of proteins. Journal of Materials Chemistry B, 4(13), 2377-2386. https://doi. org/10.1039/C6TB00178E

24. Alkaade, S., Vareedayah, A.A. (2017). A primer on exocrine pancreatic insufficiency, fat malabsorption, and fatty acid abnormalities. American Journal of Managed Care, 23(12 suppl), 203209. PMID: 28727474
25. Lee, S., Jo, K., Hur, S.J., Choi, Y.S., Kim, H.J., Jung, S. (2019). Low protein digestibility of beef puree in infant in vitro digestion model. Food Science of Animal Resources, 39(6), 1000. https://doi.org/10.5851/kosfa.2019.e73

26. Sadeghi-Kaji, S., Shareghi, B., Saboury, A.A., Farhadian, S. (2019). Spectroscopic and molecular docking studies on the interaction between spermidine and pancreatic elastase. International Journal of Biological Macromolecules, 131, 473-483. https://doi.org/10.1016/j.ijbiomac.2019.03.084

27. Xiong, L., Peng, M., Zhao, M., Liang, Z. (2020). Truncated Expression of a Carboxypeptidase A from Bovine Improves Its Enzymatic Properties and Detoxification Efficiency of Ochratoxin A. Toxins, 12(11), Article 680. https://doi.org/10.3390/toxins 12110680

28. Nakashima, Y., Miyagi-Shiohira, C., Kobayashi, N., Saitoh, I., Watanabe, M., Noguchi, H. (2017). A proteome analysis of porcine pancreatic islets and exocrine tissue by liquid chromatography with tandem mass spectrometry. Islets, 9(6), 159-176. https://doi.org/10.1080/19382014.2017.1389826

29. Ma, D., Kim, Y.H.B. (2020). Proteolytic changes of myofibrillar and small heat shock proteins in different bovine muscles during aging: Their relevance to tenderness and water-holding capacity. Meat science, 163, Article 108090. https://doi.org/10.1016/j. meatsci.2020.108090

30. Albenzio, M., Santillo, A., Caroprese, M., Della Malva, A., Marino, R. (2017). Bioactive peptides in animal food products. Foods, 6(5), 35-48. https://doi.org/10.3390/foods6050035

31. Chernukha, I.M., Fedulova, L.V., Kotenkova, E.A., Shishkin, S.S., Kovalyov, L.I. (2016). The influence of autolysis on the protein-peptide profile of Bos taurus and Sus scrofa heart and aorta tissues. Theory and Practice of Meat Processing, 1(2), 4-9. https://doi.org/10.21323/2414-438X-2016-1-2-4-9 (In Russian) 32. Bhandari, D., Rafiq, S., Gat, Y., Gat, P., Waghmare, R., Kumar, V. (2020). A review on bioactive peptides: physiological functions, bioavailability and safety. International Journal of Peptide Research and Therapeutics, 26(1), 139-150. https://doi. org/10.1007/s10989-019-09823-5

\section{AUTHOR INFORMATION}

Ekaterina R. Vasilevskaya - candidate of technical sciences, researcher, Experimental clinic-laboratory of biologically active substances of animal origin, V. M. Gorbatov Federal Research Center for Food Systems of Russian Academy of Sciences. 26, Talalikhina str., 109316, Moscow, Russia. Tel.: +7-676-95-11(128), E-mail: e.vasilevskaya@fncps.ru

ORCID: https://orcid.org/0000-0002-4752-3939

Marina A. Aryuzina - senior laboratory assistant, Experimental clinic-laboratory of biologically active substances of animal origin, V. M. Gorbatov Federal Research Center for Food Systems of Russian Academy of Sciences. 26, Talalikhina str., 109316, Moscow, Russia Tel.: +7-495-676-95-11(207), E-mail: m.aryuzina@fncps.ru ORCID: https://orcid.org/0000-0002-6886-496X

Evgeniya S. Vetrova - senior laboratory assistant, Experimental clinic-laboratory of biologically active substances of animal origin, V. M. Gorbatov Federal Research Center for Food Systems of Russian Academy of Sciences. 26, Talalikhina str., 109316, Moscow, Russia.

Tel.: +7-915-027-83-89, E-mail: jozefina-veter@yandex.ru

ORCID: http://orcid.org/ 0000-0003-2219-5964

* corresponding author

All authors bear responsibility for the work and presented data.

All authors made an equal contribution to the work.

The authors were equally involved in writing the manuscript and bear the equal responsibility for plagiarism.

The authors declare no conflict of interest. 